\title{
Ageing and Self-Care in India: Examining the Role of the Market in Determining a New Course of Growing Old among Middle Class Older Adults in Urban India
}

\author{
Jagriti Gangopadhyay ${ }^{1}$ (i)
}

Accepted: 4 August 2021 / Published online: 11 August 2021

(C) The Author(s) 2021

\begin{abstract}
With the decline of the joint family system, middle class older adults in urban India are increasingly relying on the Self-Care approach as later-life care arrangements. In particular, these older adults are relying on the market for their everyday physical and emotional care needs. Applying the North American Successful Ageing model and the political economy and consumer culture of ageing framework, the present study highlights how the market is creating a new imagination of growing old in urban India. Additionally, through qualitative interviews, the study demonstrates how perceptions regarding the ageing body among middle class older adults in urban India are gradually transforming. Finally, the study indicates how with changing filial and intergenerational ties, familial care is being replaced by the market.
\end{abstract}

Keywords Ageing $\cdot$ Market $\cdot$ Filial ties $\cdot$ Self-care $\cdot$ India

\section{Introduction}

Self-care is one of the most dominant narratives in global health policies. The main goal of the self-care model is that it requires the individual to take charge of his/ her health (Nettleton, 1995). Self-care is a concept that emerged in the 1970s in the United States of America, when healthcare practitioners suggested that leading a healthy lifestyle had a fairly good chance of reducing overall risks to an individual's health (DeFriese et al., 1989). Recently, self-care has emerged as one of the most promising methods of healthcare among the upper and middle class of India (Mishra, 2010). Expanding the self-care approach, several new private business firms are offering various home-based self-care services to the middle class ageing population of India.

Jagriti Gangopadhyay

jagriti.g@manipal.edu

1 Assistant Professor, Manipal Center for Humanities, Manipal Academy of Higher Education (MAHE), Karnataka, Manipal, India 
With the rupture of the joint family and with no support from the State, older adults in urban India who are financially stable have been relying more and more on the private sector for physical and emotional support. In recent times, several companies and start-ups have come up to cater to the needs of the elderly in India (Sharma, 2016). Start-ups such as Senior Shelf, LifeCircle, India Home Health, Beautiful years and Silver Talkies are providing healthcare, volunteers for grocery and other shopping as well as companions for the elderly (Calma, 2018; Narayanan, 2015; Ranipeta, 2017). These start-ups are particularly targeting financially well-off senior citizens who have the funds to avail of their services (Sharma, 2016). Based on qualitative interviews, the present paper highlights the significance of these startups in the lives of middle class older adults living alone in India. The paper also uses content analysis as a methodological tool to analyse the websites and brochures of these start-ups to indicate how these companies are promulgating self-care among economically independent elderly in India. Finally, the paper demonstrates how filial ties and notions around reciprocity change as later-life care shifts to the market.

\section{Existing Scholarly Studies on Self-Care in India}

Several studies in the West have demonstrated how later-life caregiving has shifted from the family to the market (Estes \& Mahakian, 2001; Gilleard \& Higgs, 2011; Katz \& Marshall, 2003; Liang \& Luo, 2012). In recent times, self-care has gained prominence in Asian and South Asian countries as well (Beglin, 2019; Mehrotra et al., 2017; Walia, 2019). Several studies have examined the importance of selfcare as a health approach for diseases such as diabetes and cardiovascular troubles in India (Ahmad et al., 2014; Gopichandran et al., 2012; Shrivastava \& Mohanty, 2013). However, all such studies have examined self-care as a universal tool and not as a particularly effective one for the elderly alone. Thus, the significance of selfcare in later-life caregiving arrangement has not been exclusively explored in the gerontological scholarship of India. Against this backdrop, the present study analyses the role of self-care as a health mechanism in the lives of middle class older adults living alone in urban India. Additionally, the study interrogates the role of the market (start-ups) in facilitating self-care in the lives of these older adults. In the process, the study also demonstrates how the market develops a new form of ethical discourse by emphasizing on self-care as a process of social control with regard to the ageing body and mind.

\section{Theoretical Frameworks}

The present study relies on the Successful Ageing model, to understand the significance of self-care in the lives of older adults. The Successful Ageing paradigm which is popular in North America, argues that lack of physical decline, engaging cognitive functions and constant activities are the means to have a satisfying old age (Rowe \& Kahn, 1997). In particular, this model suggests that following a healthy lifestyle combined with regular exercises, dietary changes and participation in social activities will enable older adults to have a productive later-life (Havighurst, 1961; 
Moody, 2009; Rowe \& Kahn, 1997). Several studies in India have applied this model and highlighted how the self becomes significant in the process of growing old (Gangopadhyay, 2016; Gangopadhyay et al., 2018; Lamb, 2009, 2014; Samanta, 2018). Adding to these studies, the present paper uses the Successful Ageing theoretical framework to demonstrate how older adults develop their own "selves" by relying on the health-based approach of self-care.

In addition to the Successful Ageing model, the present study also relies on the political economy and consumer culture of ageing model (Estes, 1993; Estes \& Mahakain, 2001; Featherstone, 1982) to understand the role of the market in inducing older adults to have a self-dependent later-life. As mentioned earlier, several studies in the West have examined how the market has substituted the family as a later-life caregiving agent (Estes \& Mahakian, 2001; Gilleard \& Higgs, 2011; Katz \& Marshall, 2003; Liang \& Luo, 2012). In particular, these studies have indicated that the market requires the individual to take responsibility for one's later-life health and well-being. Corroborating similar findings, the present study highlights how these new start-ups are creating a neoliberal culture of growing old among middle class older adults in urban India.

\section{Methodology}

The present study adopted a qualitative approach to examine how the private sector is shaping later-life care in urban India. Since the number of start-ups for older adults are gradually emerging in the economy, the study was conducted all across India. For instance, majority of the start-ups being based in Tier 1 and Tier II cities of India such as Delhi, Mumbai, Kolkata, Bengaluru, Hyderabad, Pune and Ahmedabad, the interviews were conducted in these cities only. Study participants were identified based on snowball and purposive sampling. Given that the shift from family to the market is relatively new, the study had to rely on snowball sampling (Babbie, 2012) and thus use personal contacts to recruit participants for the study. Additionally, the study employed purposive sampling (Creswell, 2013) as the study focussed on middle class older adults residing in the urban areas of India.

A total of fifty respondents were interviewed and to maintain the gender balance, twenty-five older females and twenty-five older males were interviewed. Older adults in the age group of 60-80, widowed, who was the parent of at least one adult child and who had been living alone for the last five years and had availed the services of any of these companies were included in the study. Chronically ill, permanently disabled and childless, older respondents were not interviewed for the study.

One of the primary research questions of this study was to understand how the market through these start-ups creates a new form of ageing in India. Since these start-ups which cater to the elderly population are still a new phenomenon and the older respondents relying on such start-ups are scattered all across the country, the study relied on telephonic as well as face to face interviews to explain how these start-ups are addressing later-life needs in India. A total of 27 older respondents were interviewed face to face and a total of 23 older respondents were interviewed through the telephone. Telephonic interviews as a method of 
interview have often been critiqued for its inability to provide rapport building and natural interaction with the study respondents (Holt, 2010; Novick, 2008; Shuy, 2003). However, with time several qualitative researchers have used telephonic interviews and found it be a useful method. Major advantages such as time saving, cost-effective and ensuring anonymity for sensitive topics have projected telephonic interviews as a suitable method for qualitative studies (Block \& Erskine, 2012; Burnard, 1994; Sturges \& Hanrahan, 2004). On the other hand, face to face interviews has often been described as the gold standard of qualitative research which enables the researcher to enter into direct and physical interaction with the respondent (Gerson \& Horowitz, 2002; Merriam, 2009; Patton, 2002). However, face to face interviews are expensive and time consuming as often researchers have to travel to reach the location of the respondents (Adams et al., 2007; Carr \& Worth, 2001; Irvine et al., 2012; Oltmann, 2016; Vogl, 2013). The major difference between telephonic interviews and face to face interviews is the lack of a visual encounter (Irvine et al., 2012). Taking note of the advantages and the disadvantages of both the methods, the present study relied on both these techniques to conduct qualitative interviews among its study participants.

As the study relied on snowball sampling to recruit its study participants, the author had the advantage of being introduced to the older respondents through personal contacts. As a result, trust and rapport building with the older respondents for both telephonic as well as face to face interviews took the same amount of time. The responses in both forms of interviews were the same and the respondents for both the methods took the same amount of time in responding to the questionnaire. Additionally, respondents interviewed via the telephone and respondents interviewed face to face, indicated that they were comfortable during the interviews and none of the questions had caused them any form of anxiety. All the respondents had answered all the questions and had indicated the interview (both telephonic and face to face) as a satisfying process. Thus, the present study found both these interview methods to be equally useful and no differences were found in the responses of the older respondents. The use of telephones as a mode of communication both in formal and informal settings has become very common in most cultures (Gillham, 2005). Thus it may be suggested that the present study did not observe any differences in the telephonic and face to face interviews, owing to this common usage of telephones in many contemporary societies.

The interview instrument was a semi-structured questionnaire which was developed using the deductive approach (Babbie, 2012). For example, the questionnaire was prepared post the literature review and identification of the theoretical frameworks. It had both open and close ended questions. The questionnaire was divided into four parts: Part I: (Socio-Demographic Profile) (detailed information in Table 1). which focussed on the background of the respondents, Part II: (Reasons for living alone) which had questions pertaining to why the older adult chose to live alone. Part III: (Satisfaction with the services) which focussed on how the older adult came to know about the company and measured the satisfaction rate of the older respondent with regard to the services of the company. Part IV (Policy Implications) which had questions related to policy changes regarding later-life caregiving arrangements. Post the construction of the questionnaire, in-depth and narrative style interviews were conducted. The 
interviews were conducted in Hindi, English and Bengali, owing to the linguistic limitations of the author.

Apart from interviewing older adults who use the services of these start-ups the study also relied on the method of content analysis (Mayring, 2000; Creswell, 2013) to analyse the brochures and the websites of all the major start-ups catering to elder care. To understand how these start-ups promote self-care among the older population of India, content analysis was used to examine the various tag lines, services and prices that were indicated in the brochures and websites of these start-ups (See. Table 2).

\section{Data Analysis}

All the interviews, the telephonic as well as the face to face interviews had been audio-recorded and transcribed. Once the interviews were transcribed, thematic analysis (Braun et al., 2019; Joffe \& Yardley, 2004) was used to analyse these interviews. Thematic analysis which has been used widely by gerontologists (Butcher et al., 2001; Marziali et al., 2005; Webb et al., 2015) is one of the most commonly used methods in qualitative research. Post the transcription of the interviews, the author went through the

Table 1 Socio-demographic Facts of the Older Respondents

\begin{tabular}{|c|c|}
\hline Feature & Sample Information \\
\hline Gender & Older Females (25) and Older Males (25) \\
\hline Mean Age & 72 (older females) 70 (older males) \\
\hline Religion & $\begin{array}{l}\text { Hindus (20/50 older respondents); Muslims (10/50 older respond- } \\
\text { ents); Christians (10/50 older respondents) and Jains (10/50 } \\
\text { older respondents) }\end{array}$ \\
\hline Caste & $\begin{array}{l}\text { Brahmins ( } 15 / 50 \text { older respondents); Kshatriyas }(15 / 50 \text { older } \\
\text { respondents); Vaishyas ( } 10 / 50 \text { older respondents); OBCs }(5 / 50 \\
\text { older respondents) and SCs ( } 5 / 50 \text { older respondents })\end{array}$ \\
\hline Occupation Status & $\begin{array}{l}\text { Homemaker ( } 15 \text { older female respondents); Currently working ( } 3 \\
\text { older female respondents, } 3 \text { older male respondents); Retired } \\
\text { ( } 17 \text { older male respondents, } 3 \text { older female respondents); } \\
\text { Engaged in volunteer work ( } 5 \text { older male respondents and } 4 \\
\text { older female respondents) }\end{array}$ \\
\hline Years of education & $\begin{array}{l}\text { Graduation ( } 3-4 \text { years after high school) }(20 \text { older female } \\
\text { respondents and } 5 \text { older male respondents); Post-Graduation } \\
\text { (5 years after high school) ( } 15 \text { older male respondents and } 4 \\
\text { older female respondents); PhD ( } 5 \text { older male respondents and } \\
1 \text { older female respondent) }\end{array}$ \\
\hline Average monthly household income & $\$ 722.95$ \\
\hline Main Source of Income & $\begin{array}{l}\text { Pension ( } 10 \text { older female respondents; } 13 \text { older male respond- } \\
\text { ents); Personal Savings ( } 12 \text { older female respondents and } 9 \\
\text { older male respondents); Currently working ( } 3 \text { older female } \\
\text { respondents, } 3 \text { older male respondents) }\end{array}$ \\
\hline City distribution of older respondents & $\begin{array}{l}\text { Kolkata ( } 12 \text { older respondents); Bengaluru ( } 10 \text { older respond- } \\
\text { ents); New Delhi ( } 8 \text { older respondents); Hyderabad ( } 6 \text { older } \\
\text { respondents); Mumbai ( } 5 \text { older respondents); Pune (5 older } \\
\text { respondents); Ahmedabad ( } 4 \text { older respondents) }\end{array}$ \\
\hline
\end{tabular}


data multiple times to become familiar with the data. In this process of familiarization, the author paid particular attention to patterns that occurred throughout the data. Next, the author generated codes based on how and why these patterns were occurring. Once the codes were created, the codes were combined into themes. These themes were developed by linking the codes with the main research questions and the theoretical perspectives of the study. After the themes were generated, the author went through the themes again to ensure that the themes added meaning to the data. As the themes were being finalized, the author wrote a few sentences explaining each of the themes and how each of these themes contributes to the data. Finally, before including the themes as the main findings of the study, each theme was cross-checked with some of the older respondents to ensure that each theme adds value to the narratives of the older respondents.

\section{Methodological Rigour}

To ensure Methodological Rigour the study followed the four criteria as proposed by Lincoln and Gube (1985) for qualitative studies.

Credibility: To confirm the accuracy of the interviews face to face interviews as well as the telephonic interviews were audio-recorded. To avoid missing out on minute details, every interview was transcribed verbatim immediately after each interview was over. Additionally, the final themes of the study were also double-checked with some of the study respondents.

Transferability: This feature was ensured by providing a detailed account of how the study respondents were recruited, the interviews conducted and how the data was analysed.

Dependability: To guarantee the dependability of the study, the author also reached out to nonparticipants in the same cities in India. Since similar responses and patterns were detected in the narratives of the nonparticipant older adults as well, the themes identified for the present study were confirmed as the main findings of the study.

Conformability: The author kept an audit trail consisting of the audio recordings, pattern identification and coding details, theme analysis notes to assure the conformability of the present study.

Limitations of the Study: Although the study interviewed older adults belonging to different caste, religious and ethnic groups, a cross comparison between these groups could not be conducted owing to time constraints. Additionally, the study is not an all India study and the sample cannot be a representation of the population of India. Despite, its limitations, the study is important as it examines a new and upcoming form of caregiving arrangement being practised by middle class older adults in urban India.

\section{Key Findings}

\section{Wellness Centres and their Promotion of Self-care as an Approach to Ageing}

In the post-modern era, the idea of independent ageing being pushed by the market forces have been studied in the Western context by a number of cultural gerontologists 
(Ekerdt \& Clark, 2001; Hepworth, 1995; Katz, 1999, 2000; Katz \& Marshall, 2003; Lamb, 2017; Liang \& Lao, 2012). In particular, marketing strategies are developed in a manner that highlights self-care as a successful approach during one's old age. With the development of biomedicine and geriatric clinical intervention, succumbing to old age is generally viewed as a negative process (Kauffman et al., 2004; Lamb, 2017). The biomedical discourse suggests that through dietary restrictions, exercise and high cognitive activities it is possible to arrest the physical decline and thereby have a satisfying later-life (Katz, 1999; Kaufman et al., 2004). Similar to the West, the market in India also projects this particular biomedical perspective of growing old and thus creates a new form of ageing process. Specifically, the market stresses on the role of the individual self and promotes the "self-care" method to chart an independent process of growing old among middle class older adults in India, and even promotes expensive lifestyle approaches using which one can ostensibly enjoy old age. That such promotion is successful is corroborated via the quotes below:

"I love pampering myself. These days there are so many spas and I totally spend a lot of time in these spas. There are many discounts and I think my body needs it also. You might wonder that I am old and why should I take care of my body. But why not? Youngsters these days spend so much on their bodies, why shouldn't I? I am doing it for myself. I feel good. I also eat healthy and keep up with my exercises to remain fit. I like to take care of my own body even at this age and it gives me a very refreshing feeling." (Older female respondent, aged 73).

"Men in India generally do not worry about their bodies so much. But I think times have changed. I go to a lot of ayurvedic spas and wellness centres to get a good massage. It takes away all your stress and you feel rejuvenated. I think it is needed and particularly for old people. It makes the body and the mind very fit." (Older male respondent, aged 77).

"I visit the salon once a week and also wellness centres. I also undergo a lot of physiotherapy sessions to feel active and healthy. I think aged people are ageing differently now. India is undergoing globalization and technological revolution, then why should we continue to remain fragile and dependent. It is important to take charge of your body and feel fit." (Older female respondent, aged 70).

"I do not feel old actually. I go to the gym, follow a diet and also visit many wellness centres. I also do aromatherapy to feel recharged. There are so many avenues these days for the ageing body to feel active and energized that I think I can do a lot of work and even remain healthy" (Older male respondent, aged 76).

Summarizing the quotes, it could be indicated that with the rise of the neoliberal culture and the emergence of market forces, the older adults have been persuaded to believe in self-care lifestyles. With multiple advertisements promoting anti-ageing, older adults are adopting multiple techniques to reduce the physical decline of their bodies. In particular, the market is endorsing self-care as the most ethical approach to ageing and most of the older respondents believe in this proposition as well. Thus, it may be suggested that financially stable older adults are relying on spas, salons, 
gyms and wellness centres to reinvent their ageing bodies and have an active laterlife. This finding is clearly in the line of the North American model of Successful Ageing.

\section{Start-Ups and their Packages of Healthcare and Companionships}

The market not only promulgates self-care, but it also stresses on the need to be selfreliant in later-life. Due to the lack of State support with regard to both healthcare and mental health (Lamb, 2013; Liebig \& Rajan, 2003), numerous start-ups have sprung up with healthcare options. Most of these provide various forms of healthcare and companionship services to their elderly customers. Further, these services reach right at the doorstep of the elderly. The study began by examining the tag lines of each of these companies. The tag lines of the start-ups analysed have been indicated in Table 2.

A scrutiny of the websites revealed that these companies provide the following services: assisted living, physiotherapy, nurses, safety and medical devices, care managers with regard to healthcare. Another set of services provide companions who spend time with the elderly by taking them out for a movie, or a meal or a walk, by playing games with them, buying grocery for them or sometimes simply providing conversational release. In addition to these services, some of the companies also impart technical training to older adults. The companies conduct training workshops where older adults are taught how to use the various features of smartphone and laptops. The interviews with the older participants revealed that the healthcare packages range from Rs15, 000 to Rs20, 000 and that the companionship packages range from Rs5, 000,-Rs10, 000 per month. With regard to the services of these companies, most of the older respondents mentioned that

Table 2 (Tag Lines of the Start-Ups)

\begin{tabular}{ll}
\hline Name of the Start-Up & Tag Line \\
\hline Portea & "Welcome to Portea, your new life begins at 60" \\
The Family Member & "To care for those who cared for us" \\
Maya Care & "The next best thing to family" \\
Aaji Care & "Redefining Care at Home" \\
Tribeca Care & "Bringing Healthcare at Home" \\
First Seniors & "We care for those you care for most" \\
Samvedna Senior Care & "Assisting seniors, in Delhi NCR, in ageing actively, purposefully and with \\
Silver Innings & "Fignity" \\
Healers at Home & "Healthcare at your convenience" \\
Nightingales & "Setting trends in age care" \\
Anvayaa Kin Care & "Care Comfort Convenience" \\
Life Circle & "Home nursing and professional caregiving for chronically ill and bed ridden \\
India Home Healthcare & "Providing your loved ones with $24 \times 7$ intensive care at home" \\
\hline
\end{tabular}


they were satisfied with the packages of these companies. The quotes below further elucidate these findings:

"I am quite happy with the service of this company which provides me with healthcare services right at my doorstep. I do not have to go to the hospital or visit the doctor for my physiotherapy session. I get it at my home. They are professionals and you do not have to worry about anything." (Older male respondent, aged 73).

"I live alone and going to the market is a problem. Some of the shops give home-delivery but they take their own time. These volunteers from this particular company are very good. They are on time and they do it very professionally. I am very happy with their services." (Older female respondent, aged 69).

"These companies have taken away the burden of going to the doctors or a visit to the hospital. In fact, they have doctors working for them. So there is no worry about quality. In India, even if you have money you will not get the services, but at least with the market taking over you can expect some professionalism. Hence, mostly I am happy with their performance." (Older male respondent, aged 66).

"I had fallen down and I needed a nurse. I got it from this company. She was very good. I booked her through their app and she stayed for a week and she did everything for me. Hence, these companies have definitely made life easier for us." (Older female respondent, aged 64).

Summarizing the quotes and based on the website contents, it may be suggested that many elderly respondents prefer healthcare and companionship packages provided by the start-ups. Most of the older respondents are quite content with the services of these companies. In particular, a further reading of the tag lines of these companies also indicates that they are designed in a manner to enable senior citizens to become self-reliant. Hochschild (2012), in her book, "The Outsourced Self", highlights how intimate acts such as pregnancy, weddings and caregiving of elderly parents are being outsourced to the market. In this context, the present paper applies the well-known political economy and consumer culture of ageing model (Featherstone, 1982; Estes, 1993; Estes \& Mahakian, 2001), to argue that owing to the market forces self-dependency and self-reliance is gradually replacing parental and familial care for the elderly. In particular, there is a significant role of start-up companies in advocating self-dependency to be the most successful form of ageing and in marketing their services in a manner so that older adult can have an autonomous course of ageing.

\section{Living Solo and a New Form of Dependence}

Most studies on intergenerational conflict have indicated that older adults within the family system expect respect from their adult children and their families (Gangopadhyay, 2016; Lamb, 2009; Rajan \& Kumar, 2003; Vatuk, 1990). However, these studies have also demonstrated that in spite of intergenerational tension, older parents believed in 
conforming to the normative structure of the joint family system in India and continued to live with their adult children. The present paper departs from these studies and suggests that this structure is undergoing a gradual change. In particular, this study suggests that financially independent older adults are choosing to live solo as opposed to relocating and adjusting with their adult children and their families. The quotes below further substantiate this finding:

"I used to live with my eldest son. But I felt I was more of a babysitter. They would keep the children with me and go out for their own events like watching movies and eating out. I really enjoyed with my grandchildren, but I felt I was being disrespected by my children. So I tried living with my daughter. There also same issue. I ended being a nanny. So I thought it was better to live alone. With these new companies, it is very easy. They have everything from healthcare to companions. You can depend on them. I think I am able to live alone because of these companies. In fact, I am very close to one of the female companions who comes to chat with me every day. She is aware of my all of my problems and daily issues. She knows even more than my children." (Older female respondent, aged 79).

"I tried living with my son and daughter in law. They were always nice to me and I did not have daily issues, but I was dependent on them for my mobility. I used to feel nervous to travel in Bengaluru where neither do I know the places, nor do I know the people. Hence, I used to get bored and that used to make both me and my son upset. I started expecting more time form him which he cannot give due to his hectic schedule. So I came back to Pune, where I have some friends and also I know the city well. Earlier my son was worried about my safety and health. But now with these companies he is more assured. I have hired a companion who keeps me company and also does my grocery and other daily chores. So it is better this way. We are all happier this way." (Older male respondent, aged 66).

"I used to live with my daughter and son in law. I relocated with them after my husband passed away. Initially it was nice, but later it became difficult. I did not have my personal room. I had to share my room with my granddaughter. That became a problem. Then television became another issue and for everything I was expected to compromise. So I came back to Hyderabad. Now I have this volunteer who visits me every day and we are quite close. Initially they used to send somebody new each day, but ever since I have struck a chord with this particular, person, I ask them to send only him. He is my friend, companion, helper and someone I can trust during situation of emergency. I am grateful to these companies for starting this venture." (Older female respondent, aged 67).

"I was not happy living outside Kolkata. In Delhi, the distances are huge, you have to speak in Hindi mostly and also it is difficult to make new friends at this stage. Hence, I came back to Kolkata. Also the climate in Delhi did not really suit me and I would be ill most of the times. So I was more of a nuisance to my son and daughter in law. So I rely on the doctors and volunteers of these companies. Their services are quite well and they treat you with a lot of respect. 
Both the doctors and the volunteers are very polite and since I am a regular customer, they are aware of both my health and emotional issues. Not only do I rely on them, my son is also relieved that I am in safe hands." (Older male respondent, aged 79).

A closer look at the quotes suggests that older respondents are shifting their dependence from their adult children to volunteers and physicians provided by private sector healthcare companies. In their narratives, most of the respondents mentioned that they were concerned about personal safety and that they did not trust the volunteers and companions right away. Since the companies vetted their agents and also regularly monitored their activities, eventually trust was built up. There is also the added advantage of these volunteers and companions being educated individuals with proper documents and identity cards. Thus it could be argued that laterlife dependence and expectations are shifting to these volunteers facilitated by the market.

Hochschild (2012) in her work indicated that the market creates dependence on strangers whom we permit into our intimate spaces. Additionally, the theoretical paradigm of political economy and consumer culture of ageing (Featherstone, 1982; Estes, 1993; Estes \& Mahakian, 2001) also suggests that the market by enabling the individual to become self-reliant is indirectly making them market reliant. Thus, based on the narratives of the respondents, it may be suggested that gradually the financially autonomous older adults are transitioning from depending on the family to depending on the market forces for later-life care. Addressing the emotional needs of the older population in India, the market is substituting attachment to family members with attachment to these voluntary companions.

\section{Concluding Thoughts}

This paper began by examining the rise of self-care among middle class older adults in urban India. In the process, the paper also analysed the role of the market in developing a new philosophy of active ageing. Narratives from the older respondents suggested that the biomedical and technological approach to self-care is changing perceptions regarding the ageing body. In particular, the older adults are investing a considerable amount of time and money to revamp their ageing bodies and thereby they remain fit and healthy. The other significant finding of the paper was that the self-care as a need is being accelerated by the market. Various salons, spas and wellness centres are promoting the idea of self-care and middle class older adults are falling prey to this approach. Additionally, the study also found that apart from caring for the body, several start-ups targeting the older population of India are also creating a culture of self-reliance in later-life by providing a range of services from healthcare to supplying companions right at the homes of these older respondents. Findings of the study revealed that due to these startups a large number of older adults are able to live alone instead of relocating with their adult children. Thus it may be suggested that gradually, later-life caregiving and dependence is shifting from the family to the market among financially stable 
middle class older adults in India. To conclude it may be added that by stimulating ideas of self-care and self-dependence, the market is generating an independent image of growing old in India.

Although the present study examined the significance of these self-care start-ups among middle class older adults living alone in India, these start-ups are likely to be new business ventures for housing, home care and other wellness activities and it will emerge much more in the future. As India's older population continues to grow, the number of such start-ups catering to various physical and emotional needs of the elderly will also increase. By interrogating the emergence of the self-care approach enhanced by the market in shaping an autonomous notion of growing old in India, this paper hopes to contribute to the existing gerontological scholarship in the Global South.

Funding Open access funding provided by Manipal Academy of Higher Education, Manipal. Not Applicable.

Data Availability Not Applicable.

Code Availability Not Applicable.

\section{Declarations}

Informed Consent Before the interviews began, informed consent was taken from every participant.

Ethical Treatment of Experimental Subjects (Animal and Human) Animals were not involved in this study and the human research participants were interviewed only after they gave their informed consent for the study.

Conflicts of Interest There is no conflicts of interest for this paper.

Open Access This article is licensed under a Creative Commons Attribution 4.0 International License, which permits use, sharing, adaptation, distribution and reproduction in any medium or format, as long as you give appropriate credit to the original author(s) and the source, provide a link to the Creative Commons licence, and indicate if changes were made. The images or other third party material in this article are included in the article's Creative Commons licence, unless indicated otherwise in a credit line to the material. If material is not included in the article's Creative Commons licence and your intended use is not permitted by statutory regulation or exceeds the permitted use, you will need to obtain permission directly from the copyright holder. To view a copy of this licence, visit http://creativecommons.org/ licenses/by/4.0/.

\section{References}

Adams, J., Khan, H. T. A., Raeside, R., \& White, D. (2007). Research methods for graduate business and social science students. Sage.

Ahmad, A., Patel, I., Mohanta, G., \& Balkrishnan, R. (2014). Evaluation of self-medication practices in rural area of town Sahaswan at northern India. Annals of Medical and Health Science Research, 4(Suppl 2), S73-78. https://doi.org/10.4103/2141-9248.138012

Babbie, E. (2012). Research Methods in Sociology. New Delhi: Cengage Delmar Learning India Pvt. 
Beglin, C. K. (2019). Three Ways Asians Practice Self Care. Psychology Today. Accessed at https://www. psychologytoday.com/intl/blog/culture-shocked/201904/three-ways-asians-practice-self-care

Block, E. S., \& Erskine, L. (2012). Interviewing by Telephone: Specific Considerations, Opportunities, and Challenges. International Journal of Qualitative Methods, 11(4), 428-445. https://doi.org/10. 1177/160940691201100409

Burnard, P. (1994). The telephone interview as a data collection method. Nurse Education Today, 14, 67-72. https://doi.org/10.1016/0260-6917(94)90060-4

Butcher, H. K., Holkup, P. A., Park, M., \& Maas, M. (2001). Thematic analysis of the experience of making a decision to place a family member with Alzheimer's disease in a special care unit. Research in Nursing and Health, 24(6), 470-480. https://doi.org/10.1002/nur.10005

Braun, V., Clarke, V., Hayfield, N., \& Terry, G. (2019). Thematic Analysis. In P. Liamputtong (Ed.), Handbook of Research Methods in Health Social Sciences, (pp: 1-18). Singapore: Springer. https:// doi.org/10.1007/978-981-10-2779-6_103-1.

Calma, C. (2018). Why India's Home Health Start-Ups Are Raising Serious Funding. Home HealthCare News. Accessed at https://homehealthcarenews.com/2018/01/why-indias-home-health-start-ups-areraising-serious-funding/

Carr, E. C., \& Worth, A. (2001). The use of the telephone interview for research. NT Research, 6(1), 511-524. https://doi.org/10.1177/136140960100600107

Creswell, J. W. (2013). Research Design Qualitative, Quantitative and Mixed Methods Approach. Sage.

DeFriese, G. H., Woomert, A., Guild, P. A., Steckler, A. B., \& Konrad, T.R. (1989). From activated patient to pacified activist: A study of the self-care movement in the United States. Social Science Medicine, 29(2), 195-204. https://doi.org/10.1016/0277-9536(89)90167-6.

Ekerdt, D. J., \& Clark, E. (2001). Selling retirement in financial planning advertisements. Journal of Ageing Studies, 15(1), 55-68. https://doi.org/10.1016/S0890-4065(00)00016-5

Estes, C. L. (1993). The Ageing Enterprise Revisited. The Gerontologist, 33(3), 292-298. https://doi.org/ 10.1093/geront/33.3.292

Estes, C. L., \& Mahakian, J. (2001). The political economy of productive ageing. In N. Morrow-Howell, J. E. Hinterlong, \& M. N. Sherraden (Eds.), Productive ageing: Concepts and challenges (pp. 197213). Johns Hopkins University Press.

Featherstone, M. (1982). The body in Consumer Culture. Theory, Culture and Society, 1(2), 18-33. https://doi.org/10.1177/026327648200100203

Gangopadhyay, J. (2016). Ageing across Worlds: Examining Intergenerational Relationships among Older Adults in two Cities in Transition. Ageing International, 42(4), 504-521. https://doi.org/10. 1007/s12126-016-9271-5

Gangopadhyay, J., Bapna, N., Jain, A., et al. (2018). Understanding the everyday processes of ageing in urban Delhi. Ageing International, 45(3), 255-272. https://doi.org/10.1007/s12126-018-9329-7

Gerson, K., \& Horowitz, R. (2002). Observations and interviewing: Options and choices in qualitative research. In T. May (Ed.), Qualitative research in action (pp. 201-224). Sage.

Gilleard, C., \& Higgs, P. (2011). Ageing abjection and embodiment in the fourth age. Journal of Ageing Studies, 25(2), 135-142. https://doi.org/10.1016/j.jaging.2010.08.018

Gillham, B. (2005). Research Interviewing: The range of techniques. Open University Press.

Gopichandran, V., Lyndon, S., Angel, M. K., Manayalil, B. P., Blessy, K. R., Alex, R. G., et al. (2012). Diabetes self-care activities: a community-based survey in urban southern India. The National medical journal of India, 25(1):14-7. pmid:22680314.

Havighurst, R. J. (1961). Successful ageing. The Gerontologist, 1(1), 8-13. https://doi.org/10.1093/ geront/1.1.8

Hepworth, M. (1995). Positive ageing: What is the message? In R. Bunton, S. Nettleton, \& R. Burrows (Eds.), The sociology of health promotion: Critical analysis of consumption, lifestyle and risk (pp. 176-190). Routledge.

Hochschild, A. R. (2012). The outsourced self: What happens when we pay others to live our lives for us? Henry Holt.

Holt, A. (2010). Using the telephone for narrative interviewing: A research note. Qualitative Research, 10(1), 113-121. https://doi.org/10.1177/1468794109348686

Joffe, H., \& Yardley, L. (2004). Content and thematic analysis. In D. F. Marks \& L. Yardley (Eds.), Research Methods for Clinical and Health Psychology (pp. 56-68). Sage.

Irvine, A., Drew, P., \& Sainsbury, R. (2012). "Am I not answering your questions properly?" Clarification, adequacy and responsiveness in semi-structured telephone and face-to-face interviews. Qualitative Research, 13(1), 87-106. https://doi.org/10.1177/1468794112439086 
Kaufman, S. R., Shim, J. K., \& Russ, A. J. (2004). Revisiting the biomedicalization of ageing: Clinical trends and ethical challenges. The Gerontologist, 44(6), 731-738. https://doi.org/10.1093/geront/ 44.6.731

Katz, S. (1999). Fashioning agehood: Lifestyle imagery and the commercial spirit of seniors' culture. In J. Povlsen, S. Mellemgaard, \& N. de Coninck-Smith (Eds.), Childhood and old age: Equals or opposites? (pp. 75-92). Odense University.

Katz, S. (2000). Busy bodies: Ageing, activity, and the management of everyday life. Journal of Ageing Studies, 14(2), 135-152. https://doi.org/10.1016/S0890-4065(00)80008-0

Katz, S., \& Marshall, M. (2003). New sex for old: Lifestyle, consumerism, and the ethics of ageing well. Journal of Ageing Studies, 17, 3-16. https://doi.org/10.1016/S0890-4065(02)00086-5

Lamb, S. (Ed.). (2009). Ageing and the Indian diaspora: Cosmopolitan families in India and abroad. Indiana University Press.

Lamb, S. (2013). In/dependence, Intergenerational Uncertainty, and the Ambivalent State: Perceptions of Old Age Security in India. Journal of South Asia, 36(1), 65-78. https://doi.org/10.1080/00856401. 2012.732552

Lamb, S. (2014). Permanent personhood or meaningful decline? Toward a critical anthropology of successful ageing. Journal of Ageing Studies, 29, 41-52. https://doi.org/10.1016/j.jaging.2013.12.006

Lamb, S. (2017). Successful Ageing as a Contemporary Obsession: New Jersey: Rutgers University Press.

Liang, J., \& Luo, B. (2012). Toward a discourse shift in social gerontology: From successful ageing to harmonious ageing. Journal of Ageing Studies, 26(3), 327-334. https://doi.org/10.1016/j.jaging. 2012.03.001

Liebig, P. S., \& Rajan, S. I. (Eds.). (2003). An Ageing India: Perspectives, Prospects and Policies. Haworth Press.

Lincoln, Y., \& Guba, E. (1985). Naturalistic Inquiry. Sage.

Marziali, E., Brcko, C., Climans, R., Consky, A., Munro, M., \& Tafler, M. (2005). Negotiating relationship contexts in gerontological social work practice. Journal of Gerontological Social Work, 46, 51-68. https://doi.org/10.1300/J083v46n02_05

Mayring, P. (2000). Qualitative content analysis. Forum: Qualitative Social Research, 1(2). Accessed at https://www.qualitative-research.net/index.php/fqs/article/view/1089/2385.

Mehrotra, S., Kumar, S., Gandotra, A., Sudhir, P. M., Thirthalli, J., Rao, G. N. (2017). Why urban Indians are interested in an internet-based self-care app for depression? A brief pilot survey. International Journal of Community Medicine and Public Health, 4(6): 2197-2201. https://doi. org/10.18203/2394-6040.ijcmph20173618.

Merriam, S. B. (2009). Qualitative research: A guide to design and implementation. Jossey-Bass.

Mishra, A. (2010). Deconstructing "Self-Care" in Biomedical and Public Health Discourses. In A. Mishra, (ed). Health, Illness and Medicine, (pp. 75-100). New Delhi: Orient Blackswan.

Moody, H. (2009). In J. Sokolovsky (Ed.), The cultural context of ageing: Worldwide perspectives (pp. 67-76). (3rd ed). Westport, CT: Praeger.

Narayanan, N. (2015). From elder care to entertainment, start-ups serving the $60+$ age-group are coming up fast. Scroll. Accessed at https://scroll.in/article/753937/from-elder-care-to-entertainmentstart-ups-serving-the-60-age-group-are-coming-up-fast

Nettleton, S. (1995). The Sociology of Health and Illness. Polity Press.

Novick, G. (2008). Is there a bias against telephone interviews in qualitative research? Research in Nursing and Health, 31, 391-398. https://doi.org/10.1002/nur.20259

Oltmann, S. (2016). Qualitative interviews: A methodological discussion of the interviewer and respondent contexts. Forum: Qualitative Social Research, 17(2). Retrieved from http://www. qualitative-research.net/index.php/fqs/article/view/2551

Patton, M. Q. (2002). Qualitative research and evaluation methods (3rd ed.). Sage.

Rajan, S. I., \& Kumar, S. (2003). Living arrangements among Indian elderly: new evidence from national family health survey. Economic and Political Weekly, 38(1), 75-80. Accessed at https:// www.epw.in/journal/2003/01/special-articles/living-arrangements-among-indian-elderly.html

Ranipeta, S. (2017). These startups help you care for elders, patients at home with trained professionals. The News Minute. Accessed at https://www.thenewsminute.com/article/these-startups-help-youcare-elders-patients-home-trained-professionals-72005

Rowe, J. W., \& Kahn, R. L. (1997). Successful ageing. The Gerontologist, 37(4), 433-440. https://doi. org/10.1093/geront/37.4.433

Samanta, T. (2018). The "Good Life": Third Age, Brand Modi and the cultural demise of old age in urban India. Anthropology and Ageing, 39(1), 94-104. https://doi.org/10.5195/aa.2018.208 
Sharma, M. (2016). Old is Gold: Startups for elderly hold a huge business opportunity in India. Economic Times. Accessed at https://economictimes.indiatimes.com/small-biz/startups/old-is-goldstartups-for-elderly-hold-a-huge-business-opportunity-inindia/articleshow/53664247.cms?from= mdr

Shuy, R. W. (2003). In-person versus Telephone Interviewing. In J. A. Holstein \& J. F. Gubrium (Eds.), Inside Interviewing: New Lenses, New Concerns (pp. 175-193). Sage Publications.

Srivastava, A., \& Mohanty, S. K. (2013). Age and Sex Pattern of Cardiovascular Mortality, Hospitalisation and Associated Cost in India. PLOS ONE, 8(5), e62134. https://doi.org/10.1371/journal. pone. 0062134

Sturges, J. E., \& Hanrahan, K. J. (2004). Comparing Telephone and Face-to-Face Qualitative Interviewing: A Research Note. Qualitative Research, 4(1), 107-118. https://doi.org/10.1177/1468794104041110

Vatuk, S. (1990). To Be a burden on others. In O. Lynch (Ed.), Divine passions: The social construction of emotions in India (pp. 64-91). University of California Press.

Vogl, S. (2013). Telephone versus face-to-face interviews: Mode effect on semi structured interviews with children. Sociological Methodology, 43(1), 133-177. https://doi.org/10.1177/0081175012465967

Walia, N. (2019). Self-care is the new empowerment. Times of India. Accessed at https://timesofindia. indiatimes.com/life-style/health-fitness/de-stress/self-care-is-the-new-empowerment/articleshow/ 68406498.cms

Webb, S., Chonody, J., Ranzijn, R., Bryan, J., \& Owen, M. (2015). A qualitative investigation of gerontological practice: The views of social work and psychology students, faculty and practitioners. Gerontology \& Geriatrics Education, Advanced Online Access, 37(4), 402-422. https://doi.org/10. 1080/02701960.2015.1009054

Publisher's Note Springer Nature remains neutral with regard to jurisdictional claims in published maps and institutional affiliations.

Jagriti Gangopadhyay is currently an Assistant Professor of Sociology at Manipal Centre for Humanities, Manipal Academy of Higher Education (MAHE). She did her PhD from Indian Institute of Technology Gandhinagar. For her research she has received funding from the Indian Council of Social Science Research, Kyoto University, Japan, and the University of Saskatchewan. She has published in journals of international and national repute such as Ageing International, Springer and Contributions to Indian Sociology, Sage. She has also presented her work at the Aging Studies Institute, Syracuse and the Oxford Institute of Population Aging, Oxford. 